\title{
Originals
}

\section{Islet cell and insulin autoantibodies in organ-specific autoimmune patients. Their behaviour and predictive value for the development of Type 1 (insulin-dependent) diabetes mellitus. A 10-year follow-up study}

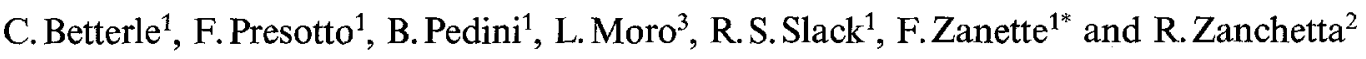 \\ Institutes of ${ }^{1}$ Medical Semeiotics and ${ }^{2}$ Human Anatomy, Padua University, Padua and ${ }^{3}$ General Hospital, Treviso, Italy
}

\begin{abstract}
Summary. To evaluate the behaviour and predictive value of islet cell and insulin autoantibodies in patients with organspecific autoimmune diseases, we followed 21 non-diabetic subjects for a mean period of $84 \pm 27$ months. Ten patients were persistently seropositive for complement-fixing islet cell antibodies and high titres of immunoglobulin $\mathrm{G}$ islet cell antibodies $(\geq 1: 8)$. The prevalence of persistent insulin autoantibodies in this group was $67 \%$. Seven patients $(70 \%)$ developed Type 1 (insulin-dependent) diabetes mellitus after a latency period of 2-60 months. The predictive value of complement-fixing islet cell antibodies was $65 \%$, and in the presence of both complement-fixing islet cell and insulin autoantibodies the predictive value rose to $76 \%$. Eleven patients were seronegative for complement-fixing islet cell antibodies and had low immunoglobulin $\mathrm{G}$ islet cell antibodies titres $(<1: 8)$ that were either persistent or transient, or that fluctuated during follow-up. The prevalence of persistent insulin
\end{abstract}

autoantibodies in this group was $45 \%$; only one subject developed Type 1 diabetes. The predictive value of persistent islet cell antibodies (complement-fixing positive/negative) was $54 \%$, and it rose to $70 \%$ when both islet cell and insulin autoantibodies were present. Individuals with only insulin autoantibodies or immunoglobulin $\mathrm{G}$ islet cell antibodies did not develop diabetes mellitus. A high frequency of HLA-DR3 and/or DR4 was found in patients who developed diabetes mellitus. Thus, the presence of both islet cell and insulin autoantibodies in patients with organ-specific autoimmune disease appears to confer the highest risk of progression toward Type 1 diabetes.

Key words: Type 1 (insulin-dependent) diabetes mellitus, autoimmune diabetes, islet cell autoantibodies, insulin autoantibodies, organ-specific autoimmune diseases.
Compelling evidence suggests that Type 1 (insulin-dependent) diabetes mellitus is a chronic autoimmune disease [1], and that autoimmune phenomena leading to B-cell destruction may be present in susceptible subjects long before the clinical onset of the disease [2,3]. Islet cell autoantibodies (ICA), especially those which fix complement (CF-ICA), are considered to be serological markers of this silent autoimmune aggression against the islets of Langerhans in first degree relatives of Type 1 diabetic patients [4], in autoimmune patients [5] and in identical twins discordant for Type 1 diabetes [6]. Insulin autoantibodies (IAA) have also been described and detected in newly diagnosed Type 1 diabetic patients before treatment [7], in identical twins [8] and in first degree relatives of Type 1 diabetic patients $[9,10]$, but their predictive value in these subjects is still under discussion.

In this work we present data on the behaviour of ICA and IAA and their relationships to the onset of

\footnotetext{
${ }^{*}$ Deceased 29 June 1986
}

Type 1 diabetes in patients with organ-specific autoimmune diseases.

\section{Subjects and methods}

\section{Subjects}

Since 1975 we began an autoantibody screening study in non-diabetic patients affected with organ-specific autoimmune diseases; this study is still in progress. Of 2049 patients screened, 42 subjects were ICA seropositive (2.4\%). Nineteen initially seropositive subjects ( 2 males and 17 females, mean age $35 \pm 19$ years) and 29 initally seronegative subjects ( 7 males and 22 females, mean age $38 \pm$ 18 years) were then periodically evaluated for the presence of ICA, CF-ICA, and for oral glucose tolerance (OGTT). Prior consent was obtained from every patient. Sera were collected and stored at $-20^{\circ} \mathrm{C}$. We retrospectively determined $\operatorname{IgG}$ and IgM class insulinbinding antibodies (IAA-IgG and IAA-IgM) on stored sera. At the start of the study all subjects had normal body weight for sex, age and height. A family history of Type 1 diabetes was present only in one subject. The patients with known endocrine deficiencies were receiving hormone replacement therapy (l-thyroxine and/or cortisone acetate). Those with active Graves' disease were treated with antithyroid drugs. 
Immunological study. ICA-IgG and complement-fixing (CF) ICA were determined according to the protocol proposed at the 1st International Workshop for the Standardization of Cytoplasmic Islet-cell Antibody Assay [11] using unfixed cryostat sections of normal human pancreas from transplant donors of blood group 0 as substrate and a sheep fluorescein isothiocyanate conjugated (FITC) serum anti-human IgG (Wellcome Reagents, Beckenham, UK) 1/40 diluted, or a rabbit FITC serum anti-human C3 (Behringwerke, Marburg, FRG) at $1 / 40$ dilution. All samples were retested on the same substrate in the same session to avoid substrate-dependent interassay variations. Undiluted sera with doubtful positivity were retested blindly three times and were considered positive if the test was positive on at least two different occasions. Titres of positive sera were determined by dilutions of the sera to the end-point with the above mentioned methods.

IAA were determined by a qualitative Enzyme Linked Immunosorbent Assay (ELISA) as recently described [10, 12] with minor modifications. The microtitre plates (Dynatech, Denkendorf, FRG) were coated with $50 \mu \mathrm{l}(250 \mathrm{ng} /$ well) of human Insulin (Novo, lot no. 1159099 , Copenhagen, Denmark) in $0.1 \mathrm{~mol} / 1$ carbonate-bicarbonate buffer, $\mathrm{pH} 9.6$, (coating buffer) containing $0.02 \%(\mathrm{w} / \mathrm{v})$ sodium azide for $8 \mathrm{~h}$ at $37^{\circ} \mathrm{C}$. All wells were then blocked for non-specific binding by incubation with phosphate buffered saline and bovine serum albumin (PBS-BSA) 3\%-Tween 20 for $12 \mathrm{~h}$ at $4{ }^{\circ} \mathrm{C}$. To microtitre plates $50 \mu \mathrm{l}$ of sera (in duplicate) diluted $1 / 100$ in PBSBSA 1\%-Tween 20 were added to each well and incubated for $1 \mathrm{~h}$ at $37^{\circ} \mathrm{C}$ in a moist chamber. At the end of the incubation period the plates were washed twice by rinsing with PBS-Tween 20 . Fifty $\mu$ of goat $F(a b) 2$ serum anti-human IgG and IgM conjugated with alkaline phosphatase (Sigma, St. Louis, Mo, USA) diluted $1 / 3000$ in PBS-BSA 1\%-Tween 20 was then added to each well and plates were incubated for $1 \mathrm{~h}$ at $37^{\circ} \mathrm{C}$ in a moist chamber. After three washings with PBS-Tween $20,200 \mu \mathrm{l}$ of p-nitrophenyl phosphate $(1 \mathrm{mg} / \mathrm{ml})$ solution in diethanolamine buffer ( $\mathrm{pH}$ 9.8) was added and the plates were maintained $1 \mathrm{~h}$ at $37^{\circ} \mathrm{C}$ in moist chamber. The reaction was stopped with $50 \mu \mathrm{l}$ of $3 \mathrm{NNaOH}$. Absorbance at $405 \mathrm{~nm}$ was measured by a photometer (Bio-Rad, Milan, Italy). The sera of 40 patients for each microtitre plate along with a blank and a positive reference curve were tested. The sera of 65 blood bank donors, who served as controls, showed an optical density of $0.086 \pm 0.03$ for IAA IgG (aspecific binding $0.011 \pm 0.006$ ), and of $0.092 \pm 0.07$ for IAA IgM (aspecific binding $0.013 \pm 0.007$ ). The specific optical density was calculated by subtraction of the non-specific value recorded in the corresponding control wells. The sera were considered positive when the absorbance values were greater than mean $\pm 2 \mathrm{SD}$ with respect to controls, namely more than 0.123 for IAA IgG and 0.205 for IAA IgM. The intra-assay coefficient of variation was $3 \%$ and $7.5 \%$ for $\operatorname{IgG}$ and $\operatorname{IgM}$, respectively. The inter-assay coefficient was $6 \%$ for IgG and $9.5 \%$ for IgM. Competitive inhibition studies using human insulin showed both IgG and IgM specificity, while the use of glucagon failed to inhibit the reaction.

Sera constantly positive during the study period were considered to be 'persistenly positive', while those which showed intermittent positivity or became negative were considered as 'not persistent'.

Table 1. Clinical, immunological, genetic and metabolic features of 21 patients with organ-specific autoimmune diseases

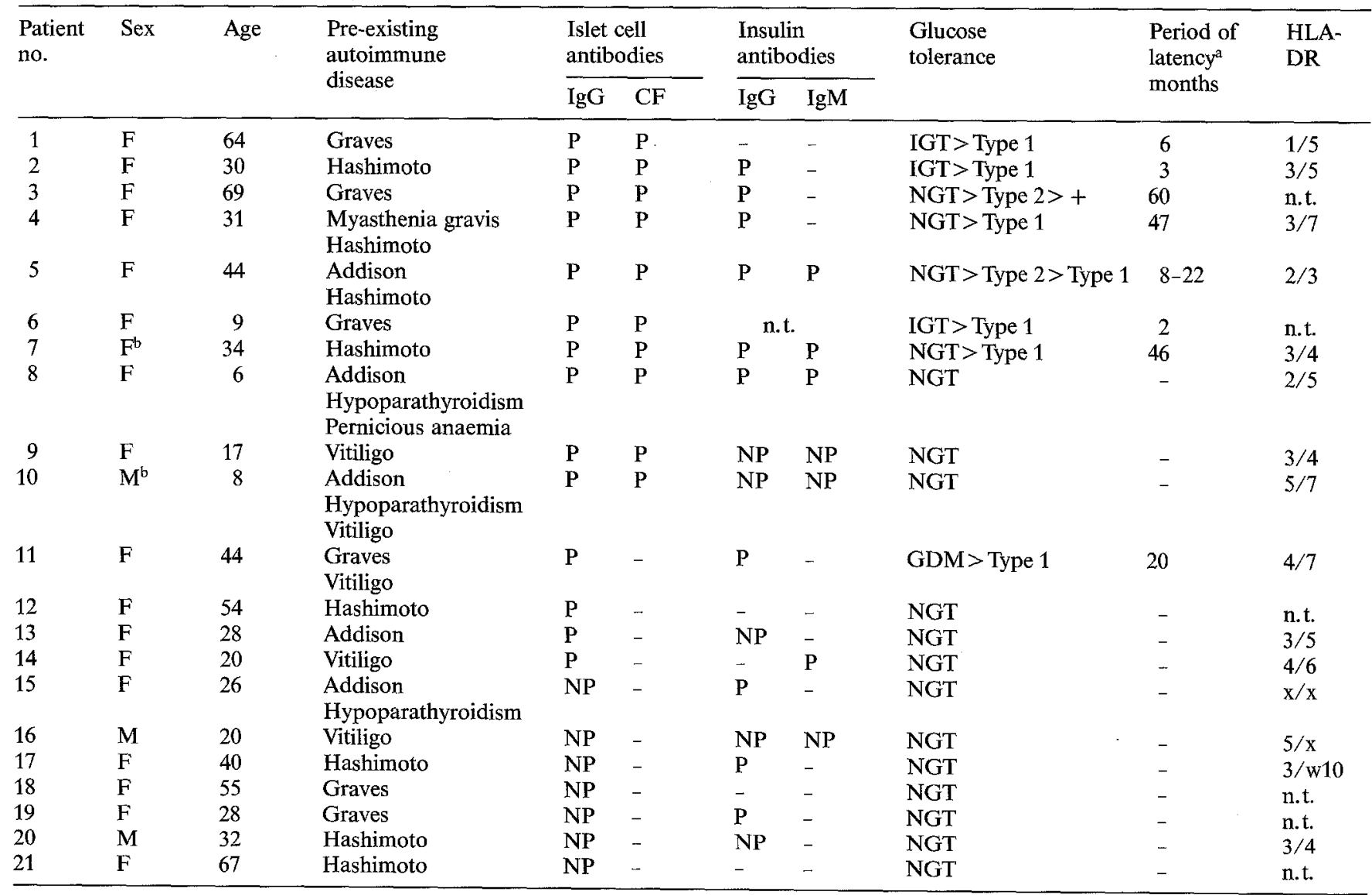

a Period of islet cell antibodies (ICA)-positivity before the onset of diabetes

b Seroconverted during follow-up

+ deceased; $\mathrm{n} . \mathrm{t}$. = not tested; $\mathrm{P}=$ persistently positive; $\mathrm{NP}=$ not persistently positive; $\mathrm{NGT}=$ normal glucose tolerance; GDM=gestational diabetes; IGT = impaired glucose tolerance; Type $1=$ insulin-dependent diabetes; Type $2=$ non-insulin-dependent diabetes; IgG/IgM=class $\mathrm{G} / \mathrm{M}$ immunoglobulins; $\mathrm{CF}=$ complement-fixing islet cell antibodies; HLA-DR $=$ human leukocyte antigens produced by $\mathrm{DR}-\mathrm{region}$ genes 
Table 2. Diagnostic value for subsequent development of diabetes of ICA, CF-ICA and IAA in terms of sensitivity, specificity, predictive values (PV) and post-test probability differences

\begin{tabular}{|c|c|c|c|c|c|c|c|}
\hline & $p$ & $\begin{array}{l}\text { Prevalence } \\
(\%)\end{array}$ & $\begin{array}{l}\text { Sensitivity } \\
(\%)\end{array}$ & $\begin{array}{l}\text { Specificity } \\
(\%)\end{array}$ & $\begin{array}{l}\mathrm{PV}+ \\
(\%)\end{array}$ & $\begin{array}{l}\mathrm{PV}- \\
(\%)\end{array}$ & $\begin{array}{l}\text { Post-test } \\
\text { probability } \\
\text { difference }\end{array}$ \\
\hline $\begin{array}{l}\text { ICA-CF } \\
(n=10)\end{array}$ & $0.00002^{\mathrm{a}}$ & 19 & 78 & 92 & 70 & 95 & 0.65 \\
\hline $\begin{array}{l}\text { IAA } \\
(n=11)\end{array}$ & $0.00088^{a}$ & 17 & 75 & 87 & 54 & 94 & 0.48 \\
\hline $\begin{array}{l}\text { ICA-CF and IAA } \\
(n=6)\end{array}$ & $0.00005^{\mathrm{b}}$ & 17 & 62 & 97 & 83 & 93 & 0.76 \\
\hline
\end{tabular}

a Compared to negative patients; ${ }^{b}$ compared to all the remaining patients

Metabolic study. On entry into the study glucose tolerance was evaluated following an oral glucose load. Glucose tolerance test and classification of diabetes mellitus were performed according to the criteria of National Diabetes Data Group [13].

Genetic study. In 15 subjects HLA-DR haplotype using a standard microlymphocytotoxicity method was determined.

\section{Statistical analysis}

Statistical significance was assessed using the Chi-square test with Yates" correction for continuity if the number in any expected class was five or less. The diagnostic value of ICA, CF-ICA, IAA and their various combinations was expressed by sensitivity, specificity and predictive values. Since the positive predictive value (post-test probability) is influenced by the prevalence of the disease, the posttest probability difference was calculated and is given by the difference between the post-test probability of disease with an abnormal test and the post-test probability of disease with a normal test at the prevalence observed [14].

\section{Results}

The 21 ICA-positive patients were subdivided into three groups on the basis of the behaviour and characteristics of ICA (see Table 1):

1. Patients persistently positive for both ICA-IgG and CF-ICA $(1-10)$. Of the 9 patients tested for IAA IgG and/or IgM, $6(2,3,4,5,7,8)$ were persistently positive. The titres of ICA-IgG ranged from 1:8 and 1:256, whereas those of CF-ICA ranged from 1:4 and 1:128. ICA-IgG titres were always higher than CF-ICA titres, and CF-ICA was never observed in the absence of ICA-IgG. In this group, six subjects developed Type 1 $(1,2,4,5,6,7)$ and one Type 2 (non-insulin-dependent) diabetes (3) after a period of observation of 2-60 months. Patient 5 developed diabetes which at first was non-insulin-dependent, but 14 months later was clearly classified as Type 1 diabetes. Patient 3 died from a myocardial infarction 6 months after the onset of non-insulin-dependent diabetes. The behaviour of ICA and IAA in these 7 cases is reported in detail in
Figure 1. Patients 1, 2 and 6 showed a slow and progressive decrease in ICA titres after the onset of Type 1 diabetes, but IAA titres decreased rapidly with the start of insulin treatment in patients 4,5 and 7 . Only 3 subjects in this group maintained a normal glucose tolerance after 62-90 months of observation; Figure 1 shows ICA and IAA behaviour in two of them $(8,10)$.

\section{Patients persistently positive for ICA-IgG but negative} for $C F-I C A(11-14)$. Two patients $(50 \%)$ were also persistently IAA-positive (11 and 14). The ICA titre ranged from $1: 2$ to $1: 8$. Patient 11 , who was seropositive for both ICA-IgG and IAA, developed Type 1 diabetes after 20 months of observation. (Fig.1).

3. Patients with non-persistent ICA-IgG (15-21). Three subjects $(15,17,19)$ were persistently IAA-IgG positive, while two $(16,20)$ showed intermittent IAA-IgG seropositivity. The ICA-IgG titre ranged from 0 to $1: 8$, and no member of this group developed diabetes mellitus.

None of the patients having persistent IAA alone (15, $17,19)$ or persistent ICA-IgG alone $(12,13)$ developed diabetes mellitus.

HLA haplotypes are reported in Table 1 . Out of the eight ICA-positive patients who developed diabetes mellitus, three had HLA-DR3, one DR3/4, one DR4, one DR1/5 and two were not detectable.

Out of 29 ICA-negative patients with organ-specific autoimmune diseases, two showed seroconversion for ICA and IAA after 43-47 months and were therefore included in ICA-positive group $(7,10$ in Table 1 and Fig. 1). Patient 7 developed Type 1 diabetes

Fig. 1. Behaviour of the various immunological parameters in patients who developed diabetes mellitus $(1-7,11)$ and in two still normal patients $(8,10) . \bigcap=$ onset of Type 2 diabetes; $\downarrow=$ onset of Type 1 diabetes. Insulin autoantibodies (IAA) expressed in optical density at $405 \mathrm{~nm}$; the cut-off for IAA-IgG was 0.123 , and for IAA-IgM 0.205. Islet cell autoantibodies (ICA) expressed as titres 
C. Betterle et ấ: Islet cell and insulin autoantibodies in autoimmune endocrinopathies
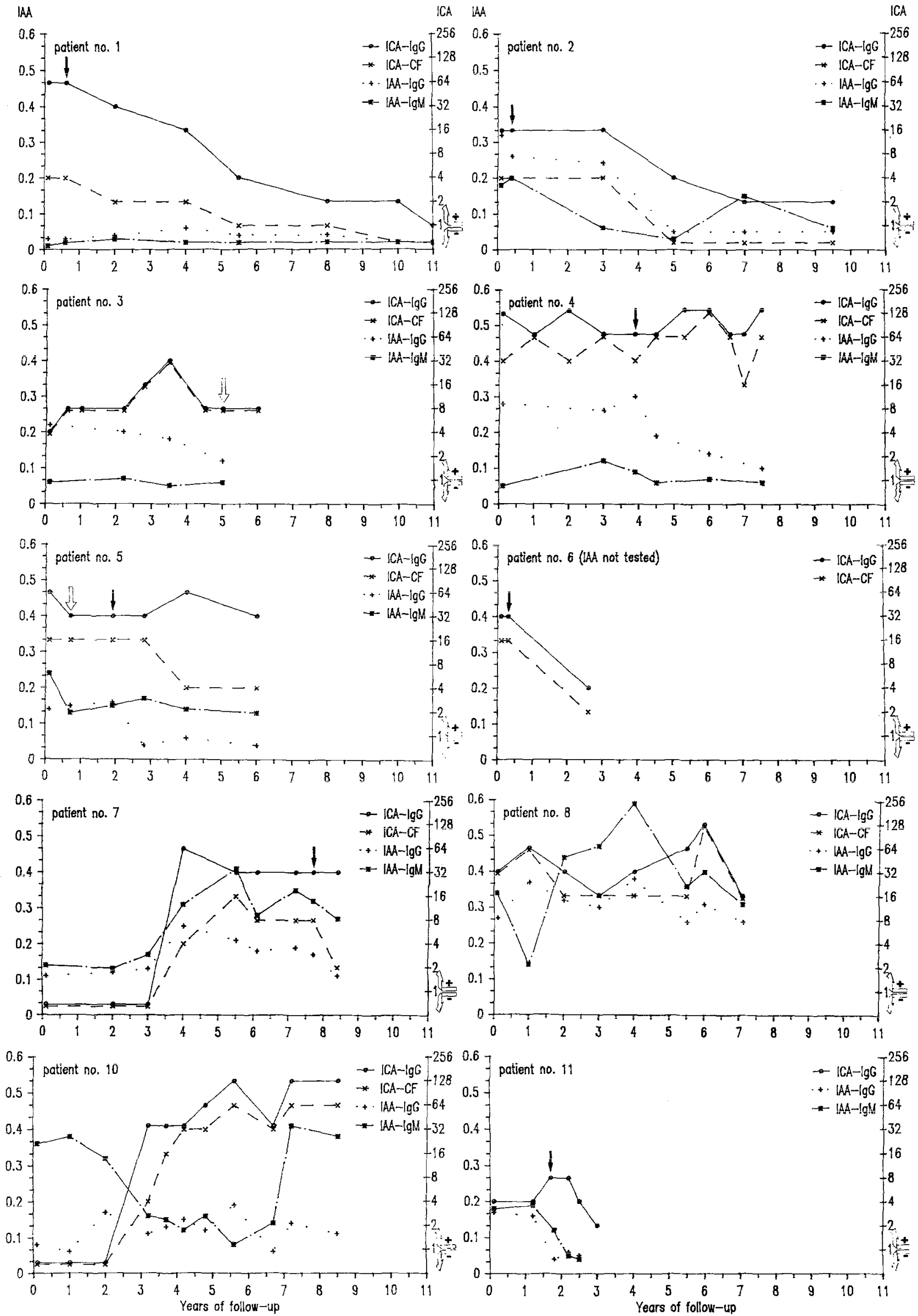

$\rightarrow \operatorname{ICA}-\lg G T_{-128}^{256}$

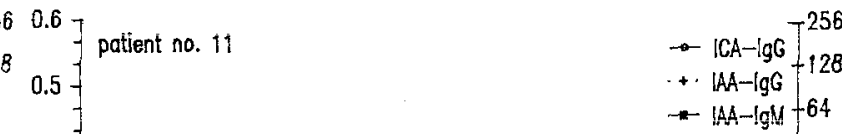

- IAA-Igy -64

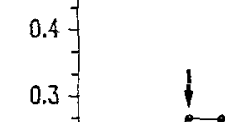

0.3

$-2$
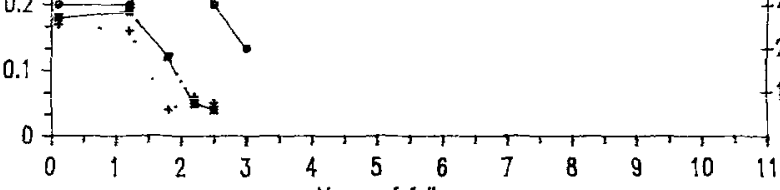
46 months after seroconversion, whereas patient 10 is still non-diabetic after 72 months from seroconversion (Fig.1). The remaining 27 subjects were persistently negative for both autoantibodies, and one developed Type 1 diabetes after 37 months.

The diagnostic value of ICA, CF-ICA and IAA in terms of their sensitivity, specificity and predictibility are summarized in Table 2. Given the strict association of ICA and IAA, and having few cases with either ICA-IgG or IAA seropositivity alone, a positive predictive value for either marker alone cannot be calculated.

\section{Discussion}

The presence of islet cell autoantibodies, particularly those which fix complement, has been used to identify the high risk of diabetes in genetically susceptible individuals in insulin-dependent diabetic families [4].

In the present study, we evaluated the behaviour and predictive value of ICA and IAA in patients with organ-specific autoimmune diseases by following a group of non-diabetic subjects. The value of ICA in predicting potential diabetes mellitus in these patients appears to be most strongly associated with their ability to fix complement (predictive value $=65 \%$ ). That patients with CF-ICA have high ICA-IgG titres and those with low ICA-IgG titres do not fix complement suggests that CF-ICA are not a separate immunological entity, as previously reported [4], but simply the expression of high titres of circulating ICA-IgG. Further studies to isolate and characterize islet cell antigens will clarify this issue.

In ICA seropositive patients with organ-specific autoimmune diseases, the presence of CF-ICA and/or IAA is frequent. Diabetes mellitus developed more frequently in those patients who were seropositive for both CF-ICA and IAA than in those with CF-ICA alone, or in those with both ICA-IgG and IAA. At present, none of our patients with either ICA-IgG or IAA alone have developed overt disease. Similar results are seen in first degree relatives of Type 1 diabetic patients [10]. These data bring into question the value of the presence of ICA-IgG and IAA alone in predicting the progression to diabetes mellitus in susceptible individuals.

In general, the clinical onset of diabetes in our patients was acute and required insulin therapy, but in two subjects the disease appeared as Type 2 (non-insulin-dependent) diabetes. Following the onset of Type 1 diabetes, patients. showed a slow decrease in ICA titres, but maintained ICA positivity. The IAA titres decreased rapidly or became undetectable after the start of insulin treatment, probably because of immunocomplex formation. The clinical and immunological characteristics observed in our patients are similar to those of the previously described autoimmune form of dia- betes mellitus known as Type $1 \mathrm{~B}$ [15]. These patients are generally middle-aged females, with pre-existing organ-specific autoimmune manifestations, are prevalently HLA-DR3 positive, and show persistent ICA seropositivity before and after the onset of insulin dependency which is sometimes preceded by a period of Type 2 diabetes.

The data suggest that, as in family studies where ICA and IAA confer a higher risk for the development of diabetes because of the presence of affected relatives, in patients with organ-specific autoimmune diseases the presence of ICA and IAA identifies a group of potential diabetic patients due to co-existing autoimmunity. In both cases, however, a genetic predisposition seems to be an important co-factor in the potential development of the disease.

Although immunotherapy is imminent, its clinical use remains to be evaluated. Only when the innermost mechanisms of immune reactions are understood, specific immunotherapy will become a standard tool in the clinical management of diabetes. The present study sheds further light on factors that confer high susceptibility for developing diabetes in autoimmune patients. In this cohort of individuals, where the damage to $B$ cells is autoimmune, and the number and the function of B cells have not been completely compromised, the initiation of an early immunosuppressive therapy might be of benefit.

Acknowledgments. We thank Dr. C. Scalici and Prof. P. Drew for their invaluable assistance on this project. This work was supported by Research Grants (nos.850045556 and 860167858) from Consiglio Nazionale delle Ricerche (CNR) Rome, Italy: target project "Preventive Medicine and Rehabilitation", subproject "Degenerative Diseases", object "Study of Immunological and Genetic Aspects of IDDM".

\section{References}

1. Eisenbarth GS (1986) Type I diabetes mellitus: a chronic autoimmune disease. N Engl J Med 314: 1360-1368

2. Bottazzo GF, Florin-Christensen A, Doniach D (1974) Islet cell antibodies in diabetes mellitus with autoimmune polyendocrine deficiences. Lancet 2: 1279-1283

3. Betterle C, Tessari P, Fodale R, Tiengo A (1980) A three years immunological and metabolic follow-up in 18 ICA-positive subjects. In: Pinchera A, Doniach D, Fenzi GF, Baschieri L (eds) Autoimmune aspects of endocrine disorders. Academic Press, London, pp 295-298

4. Bottazzo GF, Dean BM, Gorsuch AN, Cudworth AG, Doniach D (1980) Complement fixing islet cell antibodies in type I diabetes: possible monitors of active beta-cell damage. Lancet 1 : 668-672

5. Betterle C, Zanette F, Tiengo A, Trevisan A (1982) Five year follow-up of non-diabetics with islet-cell antibodies. Lancet 1: 284-285

6. Srikanta S, Ganda OP, Eisenbarth GS, Soeldner JS (1983) Islet cell antibodies and beta-cell function in monozygotic triplets and twins initially discordant for type I diabetes mellitus. $\mathbf{N}$ Engl $\mathbf{J}$ Med 6: 322-325 
7. Palmer JP, Asplin CM, Clemons $\mathrm{P}$, Lyen $\mathrm{K}$, Tatpati $\mathrm{O}$, Raghu PK, Paquette TKL (1983) Insulin antibodies in insulin-dependent diabetes before insulin treatment. Science 222: 1337-1339

8. Wilkin T, Hoskins PI, Armitage M, Rodier M, Casey C, Diaz JL, Pyke DA, Leslie RDG (1985) Value of insulin autoantibodies as serum markers for Insulin dependent diabetes mellitus. Lancet 1: $480-482$

9. Srikanta S, Ricker AT, McCulloch DK, Soeldner JS, Eisenbarth GS, Palmer JP (1986) Autoimmunity to insulin, beta-cell dysfunction and development of insulin dependent diabetes mellitus. Diabetes 35: 139-142

10. Dean BM, Becker F, McNally JM, Tarn AC, Schwartz G, Gale EAM, Bottazzo GF (1986) Insulin autoantibodies in the pre-diabetic period: correlation with islet cell antibodies and development of diabetes. Diabetologia 29: 339-342

11. Gleichmann H, Bottazzo GF (1987) Progress towards standardization of the Cytoplasmic of the Islet-Cell Antibody Assay: Analysis of the Data presented at the First International Workshop. Diabetes (in press)

12. Wilkin T, Nicholson S, Casey C (1985) A micro enzyme-linked immunosorbent assay for insulin antibodies in serum. J Immunol Methods 76: 185-194

13. National Diabetes Data Group (1979) Classification and diagnosis of diabetes mellitus and other categories of glucose intolerance. Diabetes 28: 1039-1057

14. Hamilton GW, Trobaugh GB, Ritchie GL, Gould KL, DeRouen TA, Williams DL (1978) Myocardial imaging with 201-Thallium: an analysis of clinical usefulness based on Bayes' theoreme. Semin Nucl Med 7: 358-364

15. Bottazzo GF, Doniach D (1976) Pancreatic autoimmunity and HLA antigens. Lancet 2: 800

Received: 17 September 1986

and in revised form: 3 March 1987

Dr. Corrado Betterle

Institute of Semeiotica Medica

via Ospedale Civile, 105

I-35128-Padua

Italy 